\section{Focal style and freedom of movement}

Castellini is dedicated to providing dentists with first class dental units with cutting edge technology, reliability and comfort.

Combining exclusive Italian style and innovation, the Skema 8 dental unit is suitable for every practice whatever your specialisation.

This outstanding unit will transform your treatment room - with a unique sliding function to optimise space, patients can easily be repositioned without moving the operating light. The exceptional ergonomic design also features all the positions for classic two-handed or four-handed procedures, so you can deliver excellent patient care and treatment in any clinical situation.

From help with purchasing to unrivalled aftercare support and maintenance, Castellini's sales and service centres throughout the UK offer fast, efficient assistance that you can count on.

For advice from experts with a passion for dentistry, call 08000933975 and speak to Castellini UK directly for assistance.

\section{Have you started planning?}

Have you started planning for your retirement? If not, it might be time to map out your strategy. Naturally, the earlier you start the better, as it will help to reduce the pressure of saving, whilst accruing more money along the way. By delaying your investments you put yourself in a position where you have to save more aggressively, which could in turn have a negative impact on your other financial goals or responsibilities.

To give you the best outcome, money4 dentists will work with you to forecast the sum you'll need for retirement, select and manage appropriate assets and calculate a manageable savings plan in line with your current earnings.

The team of Independent Financial Advisers at money4dentists has a great record for guiding dentists efficiently, effectively and profitably through their financial decisions, and is unmatched in its understanding of dentists' unique needs.

For more information call 0845345 5060, email info@money4dentists.com or visit www.money4dentists.com.

\section{Encourage your patients to start babies' oral care from birth}

Brush-Baby, the specialist oral health company for babies and children, understands the importance of the earliest adoption of an oral care routine for babies to help them learn to love the dentist and enjoy cleaning their teeth as they get older.

Brush-Baby has developed a range of dental wipes, teething wipes, teethers and first brushes and toothpastes to encourage parents to routinely clean their babies' gums and mouths. This includes:

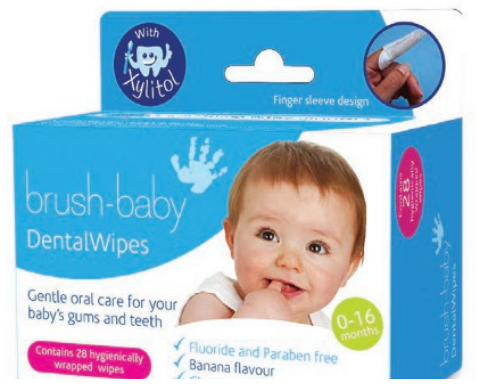

- Brush-Baby DentalWipes for 0-16 months, with their finger sleeve design clean baby gums and teeth. They are gently formulated with xylitol to reduce decay-causing bacteria. RRP $£ 4.99$ for 28 wipes
- Brush-Baby TeethingWipes for 0-16 months, with all the benefits of the DentalWipes plus camomile to soothe teething gums. RRP $£ 4.99$ for 20 wipes

- Brush-Baby My FirstBrush for 0-18 months, with its tiny brush head for first baby teeth and soft bristles which are gentle on delicate gums - cleverly combined with a long handle for adult hands. RRP $£ 2.10$

- NEW Brush-Baby My FirstBrush \& My FirstTeether Set for 0-18 months, with soft bristles, My FirstTeether helps to massage gums and clean teeth, whilst providing comfort for gums with its firm surface. The easygrip handle suits little hands and the 'Flower Guard' clips in for your baby’s safety. RRP $£ 6.75$

- Brush-Baby Teething Toothpaste for 0-2 years, with its gentle applemint flavour, xylitol to neutralise sugar acid, camomile to soothe gums and low fluoride (500 parts per million) to help strengthen the tooth's enamel whilst being safer if swallowed. RRP $£ 2.35$ for $50 \mathrm{ml}$.

Visit www.brushbaby.co.uk for more information.

\section{Get a handle on articulation}

Measuring a patient's occlusion is an essential part of effective dentistry. Unfortunately, it can also be quite fiddly - especially if you are using articulation paper. The paper needs cutting to size and then must be held in place with articulation forceps, which patients do not enjoy having in their mouths.

Luckily, Dental Express, a trading division of Surgery Express, has an excellent alternative. As the exclusive UK suppliers of Bitechek, the Dental Express team is helping practitioners get a handle on articulation.

The Bitechek is a unique product that features a built-in handle that keeps the paper stiff. This not only enables easy handling and positioning, but also eliminates the need for forceps: good news for the patient and good news for your sterilisation costs!

What's more, the Bitechek is quick and convenient to use, and exhibits the ideal level of stiffness to avoid curling during the occlusal analysis procedure.
Ultimately, this allows for more accurate occlusal measurements and better overall treatment.

Available from Dental Express, one of the UK's foremost suppliers of dental consumables, Bitechek is a must-have for any dental surgery. Contact the team to find out more.

For more information, visit www.surgeryexpress.co.uk, call on 08006888 992 or email sales@surgeryexpress.co.uk.

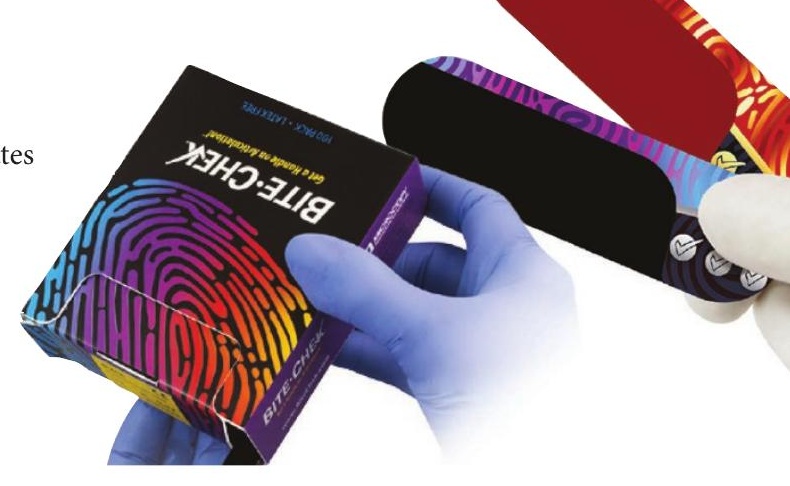

